\title{
Crônica de um verão e Jogo de cena: tecendo outros cotidianos ${ }^{1}$
}

Míriam Cristina Carlos Silva²

1 Uma versão reduzida deste artigo foi apresentada no congresso Lusocom, em Lisboa, em outubro de 2012.

2 Professora titular do Mestrado em Comunicação e Cultura da Universidade de Sorocaba - SP - UNISO. Doutora e Comunicação e Semiótica. micriscarlos@uol.com.br. 


\section{Resumo}

Este artigo analisa o documentário como um processo experimental de linguagem, no qual o cotidiano é explicitado para servir como possibilidade de reflexão e crítica. Discute-se o recorte realizado pelo diretor, que se torna também narrador: aquele que ouve e realiza a mediação da experiência relatada por seus entrevistados. A partir das aproximações entre Crônica de um verão, de Jean Rouch, e Jogo de cena, de Eduardo Coutinho, fica demonstrada a possibilidade da prática destes documentaristas como um método de pesquisa, ou melhor, como metáporo - na proposição de Marcondes - do qual se pode extrair, também, um conceito de comunicação.

\section{Palavras-chave}

Crônica de um verão, Jogo de cena, documentário.

\section{Abstract}

This article examines the documentary as an experimental language process, in which everyday life is exposed as to open the possibility for reflection and critique. We discuss the trimming done by the director, who also becomes the narrator: one who listens and performs the mediation of the experiences reported by the interviewees. Through the similarities between Chronicle of a summer (Jean Rouch), and Jogo de cena (Eduardo Coutinho) the possibility of the documentary practice as a research method, or rather as metáporo (C. Marcondes), is demonstrated. We can also gather from it a notion of communication.

\section{Keywords}

Chronicle of a summer, Jogo de cena, documentary. 
O documentário, de modo genérico, já foi o formato privilegiado para se apresentar a realidade de forma denotativa, ou seja, referencial. No Brasil, como em outras partes do mundo, antes de ser praticado por cineastas, cumpriu a função de ser uma ferramenta de trabalho nas pesquisas etnográficas. De forma que não seria incorreto afirmar que os antropólogos estão entre os pioneiros na produção documental brasileira e que, também, o documentário serviu ao método da pesquisa participativa, na qual o pesquisador se mistura ao objeto que será investigado. Gonçalves explica que: "O filme Rituais e festas Bororo, de 1917, é considerado pela crítica cinematográfica como uma das primeiras experiências de sucesso na montagem cinematográfica do cinema brasileiro, além de um dos primeiros filmes antropológicos do mundo" (GONÇALVES, 2006, p. 81). Trata-se de um filme pioneiro não somente no cinema documentário brasileiro, mas também no panorama do cinema etnográfico internacional, por ser um dos primeiros filmes antropológicos, realizado pelo major Luiz Thomaz Reis, com a Comissão Rondon.

Outra vertente documental praticada no Brasil foi a de filmes didáticos ou de caráter institucional. Por trinta anos à frente do Instituto Nacional do Cinema Educativo, criado em 1936, Humberto Mauro teve uma produção profícua em documentários de caráter didático:

\footnotetext{
Mauro realizou 354 filmes educativos curtos no período e, apesar da natureza oficial e didática do material produzido, conseguiu imprimir uma estética pessoal à maioria de seus trabalhos, além de tornar o INCE num fértil centro de produção de curtas e médias-metragens. São produzidas séries de documentários rurais, de fauna e flora, de instituições e de cerimônias oficiais, mas predominam os filmes científicos. Em 1945, Mauro inicia a série de documentários denominada Brasilianas, com sete filmes de curta-metragem, que registram canções tradicionais do folclore brasileiro (GONÇALVES, 2006, p. 82).
}

No caso dos filmes de Mauro, fica claro que se trata de fornecer informação ao espectador. Entretanto, já se trata de informação direcionada, pois que "o 
Instituto pretendia mostrar uma imagem positivista do Brasil, com intenção de democratizar o conhecimento partindo das classes intelectualizadas para as desfavorecidas" (GONÇALVES, 2006, p. 81).

Porém, se a origem do documentário brasileiro é claramente calcada em uma linguagem denotativa, a partir da década de 70, o documentário feito no país passa a figurar como uma construção na qual se misturam o sujeito produtor, na figura do cineasta ou documentarista, e realidade a ser retratada. Assume-se um ponto de vista como um recorte necessário para a supressão de uma barreira de objetividade e imparcialidade diante daquilo que é filmado. A experimentação estética ganha força:

Em 1974, Arthur Omar realiza o longa-metragem Triste trópico, filme que desenvolve experimentações iniciadas em filmes de curta-metragem produzidos anteriormente, questionando o gênero documental enquanto reprodução do real e utilizando uma linguagem experimental, fragmentada e ambígua (GONÇALVES, 2006, p. 85).

Vale ressaltar que uma das experiências mais ricas, nascida a partir das influências do cinema etnográfico, na experimentação com a linguagem documental, não no Brasil, mas na França, data da década de 60, com o filme Crônica de um verão, de Jean Rouch e Edgar Morin. J. Rouch, que viria a ser uma influência universal para o cinema, era formado em engenharia. No exercício da profissão, na África, sensibilizou-se com as mazelas causadas pelo colonialismo europeu. Interessou-se pela etnografia e estudou com M. Mauss. Em 60, etnólogo formado e já um cineasta experiente, nitidamente influenciado por D. Vertov, junta-se a Edgar Morin, que traz a sua contribuição reflexiva de sociólogo. E. Morin atribui a J. Rouch, na experiência com Crônica de um verão, a característica de "cineasta-mergulhador" (MORIN, 2008). A ideia era fazer um filme em que os realizadores mergulhassem no cotidiano de seus personagens e fizessem, dali, emergir um universo particular - o homem visto em suas peculiaridades e angústias - mas ao mesmo tempo em uma abordagem de 
questões universais, por isso o mote com uma pergunta que escondia inúmeras camadas: você é feliz?

Para o intento, J. Rouch opta por utilizar uma câmera de 16 mm e um gravador portátil. Com um aparato técnico pequeno e uma equipe mínima, considera mais fácil penetrar no universo das personagens, mover-se entre elas e com elas. É claro que o equipamento ostentado de forma grandiloquente pode vir a falar mais do que aquilo que se investiga - toma a voz dos entrevistados, oferece-Ihes máscaras e uma possibilidade de encenação em que o contraponto é a própria câmera. Deste modo, J. Rouch aceita a imperfeição técnica do som e da imagem para poder transitar com maior facilidade entre aquilo que deseja captar. O documentário é encarado, neste caso, como pesquisa, mas pesquisa participativa, na qual os realizadores são também objetos da filmagem. Nesta busca por um novo "cinemaverdade", o que conta, segundo E. Morin (MORIN, 2008), é também a criação de um "cinema-fraternidade", no qual o espectador se vê irmanado com os sujeitos da tela, menos diferente dos outros homens. Numa espécie de sociodrama, há a tentativa de se despir de algumas máscaras e encenar a própria vida e, assim, o que está oculto ou reprimido volta à superfície. Ocorre uma forma de psicodrama coletivo entre atores e personagens. Neste caso, o documentário não tem como objetivo uma pura descrição da realidade, a informação de fatos, a apresentação de feitos heroicos, mas sim proporcionar uma vivência, uma experiência coletiva. E esta experiência se dá a partir de dois métodos essenciais, apontados por E. Morin (MORIN, 2008): a comensalidade - são realizadas reuniões com jantares coletivos, nos quais se oferece boa comida e se rega com um bom vinho. Quebrase a imposição da câmera por meio da espontaneidade, da informalidade, da empatia e da comunicação geradas pela refeição em comum. Outro método é a pedovisão: enquanto os personagens caminham pela cidade, conversando, sorrindo, observando, discutindo, a câmera os acompanha.

Nenhuma pergunta é preparada previamente, mas há um roteiro de temas, que pressupõe um estudo em três níveis: 1) o da vida privada, que é o da vida interna e subjetiva; 2) o do trabalho e das relações sociais e 3) o da 
história atual. Em meio aos temas programados, a improvisação, o acaso e a experiência ganham destaque.

Em relação à estética cinematográfica, opera-se com um enquadramento que deve seguir o evento, em uma comunicação telepática entre o cinegrafista e a cena (MORIN, 2008). Assim, nem sempre o rosto mais expressivo é o de quem está falando, por isso, mais do que de talento, o cinegrafista necessita de empatia e comunicação (MORIN, 2008).

O caso de Crônica de um verão é exemplar de como aspectos objetivos e subjetivos, denotativos e conotativos podem se misturar. O documentário no Brasil nasce com a característica da preponderância de uma linguagem denotativa, objetiva, com o filme etnográfico e o didático, em que muitas vezes há uma dissociação entre imagem, posta como elemento meramente ilustrativo, e narrativa verbal. Logo se percebe que esta realidade, passada a documentário, mesmo nestes casos, já não é mais realidade vista como documento incontestável, mas sim signo, representação, recriação ou interpretação do real. Nesta representação interferem inúmeros olhares que servem como tesouras para recortar parcialmente o que se pretende exibir: há o recorte do roteirista, o do diretor, o do fotógrafo, o do editor. E mais que isso, há a possibilidade de que o filme se transforme em uma experiência psicodramática, um momento de explosão na esfera da subjetividade, naquilo que ela tem de íntimo e ao mesmo tempo universal. A imprevisibilidade das reações ao que é perguntado e a mudança de foco - em alguns momentos o enquadramento se desloca para alguém da equipe - possibilitam essa experiência de real, de cotidiano, de incorporação de uma fatia da vida com todas as suas contradições e confusões.

De J. Rouch e E. Morin, na França, a Eduardo Coutinho, no Brasil, entre outros, o formato documental parece estar cada vez mais distante e desvinculado do compromisso de relato fiel da realidade, sobretudo contemporaneamente, quando a tônica das obras artísticas e comunicacionais é mesclar os gêneros. Não há rigidez possível. O que há é intercâmbio, intersemiose, hibridização. 
Mais que um documento da realidade, cada vez mais o documentário expressa um ponto de vista, e não o único possível, pois que se trata de uma dentre as inúmeras formas possíveis de se representar esta realidade, portanto, um signo. Um filme, ainda que documental, não é a realidade, mas é uma representação parcial, sempre parcial, dessa realidade.

\section{Jogo de cena}

Passamos, então, ao recorte realizado no filme Jogo de cena (2007) por Eduardo Coutinho, documentarista com passagem pelo teatro e pelo jornalismo, realizou, dentre seus muitos trabalhos, Cabra marcado para morrer, que levaria quase 20 anos para ser concluído, por percalços enfrentados com o regime militar. Apesar de ter trabalhado com o cinema ficcional e de ter se especializado em roteiro, foi com a linguagem do documentário que construiu seu estilo, caracterizado por um intenso humanismo e uma extraordinária capacidade de saber ouvir. Coutinho explora a complexidade da obra artística, brincando com o gênero ou formato que ele produz. Oitenta e três mulheres atendem a um anúncio de jornal e fornecem seus depoimentos em um teatro, Glauce Rocha, que serviu como estúdio. Destas, são selecionadas vinte e três. Ainda, atrizes interpretam histórias selecionadas dos depoimentos.

Há, nesta produção audiovisual, uma espécie de processo em comunicação orquestral, no qual o diretor rege inúmeras vozes, que passam pela equipe técnica e também pelos atores diretos daquilo que é documentado. No caso de Jogo de cena, mulheres comuns, que contam as suas vidas e também atrizes que, além de representarem as histórias selecionadas, relatam como compuseram seus personagens. Processos interpretativos, dramáticos, ensaiados e encenados pelas atrizes, confundem-se com as vidas relatadas por suas próprias protagonistas. Os relatos, então, são recontados, reencantados, revividos. Realidade e ficção se mesclam e confundem o espectador. 
Portanto, como espectador, há que se ficar alerta. Coutinho não traz à tona simplesmente o real. Trata-se do possível, do verossímil e, ao mesmo tempo, do fantástico, do absurdo que todo verossímil guarda em si. Ele traz apenas um recorte, recriado, deste real. Entretanto, Coutinho investe em uma face complexa desta possibilidade de real. O diretor, mais do que um documentarista, é um artista do audiovisual, portanto, sua obra, recorte parcial da realidade, recriação, é a manifestação de realidades possíveis, interpretadas por seu olhar arguto e apresentadas em uma linguagem que assume uma forma específica e não casual. Se estas realidades possíveis correspondem a ações factuais, não importa. Importa o modo como Coutinho apresenta estas várias possibilidades de real. No filme Jogo de cena, o texto, e aqui se entenda o texto como uma estrutura de códigos elaborados para produzir sentido, é montado de forma complexa, na acepção de Y. Lotman (1978), para quem um texto artístico é um texto construído com complexidade. Todos os elementos são elementos de sentido. Em um texto artístico, a forma é, ela mesma, o conteúdo. Nada é aleatório e cada detalhe mínimo compõe a construção de sentidos. Trata-se de uma construção econômica que permite comunicar muito, com poucos elementos.

Não existe nenhuma informação supérflua. A tensão, a expectativa, a ansiedade são iconizadas pelas personagens que sobem as escadas, inquietas, ofegantes, sedutoras e que encenam, em um palco sem cenário e em um filme sem trilha, sem figurino, sem objetos de cena, a sua história, que se faz presente no momento em que é narrada. O tempo da narrativa é sempre o presente da narração. É a crueza do teatro de atores, o chamado teatro pobre, de J. Grotowsky (1987), em diálogo com a simulada crueza da câmera objetiva. Não há música, a não ser aquela produzida pelos sons do ambiente, pelos corpos que se deslocam, que se sentam. Pelo tom de voz que vacila, que acompanha o pulsar do coração, o desenhar das mãos, a respiração. Tudo é limpo e ao mesmo tempo rico e intenso, sugestivo. Poucos planos e enquadramentos, mas muitos olhares e cenhos que os acompanham, bocas que se abrem e se contêm, 
espaços que amparam o olhar do espectador, vazios que se completam com as vidas que espreitam outras vidas contadas na tela. Cortes secos. Mas há, sem dúvida, uma edição. E é ela que costura e dá sentido à narrativa. Portanto, transforma ou reconta a trama de tramas que se misturam, porque algo em comum as une: todas são mulheres, todas estão vivas, apesar das dores que todas quiseram, por algum motivo, relatar. Todos são relatos do cotidiano, com a banalidade, a poesia e a universalidade que permitem que qualquer um se identifique com ele: a vida e a morte insinuando-se em cada situação vivida ou apenas verossimilhante.

Todas são atrizes e mulheres comuns, detentoras de narrativas que se confundem, misturam-se e se contradizem e reeditam seus relatos a partir da rememoração, já que a memória transfigura o real ao fazê-lo presente. Difícil é especificar quem é mais e quem é menos atriz, mas todas o são, de algum modo, pois representam sua própria vida na tela, para a câmera, para o diretor e sua equipe. Todas são narradoras/personagens em um palco sem cenário, limpo, conotando que todas estão de cara limpa. Trata-se de uma ilusão, pois que todo mínimo movimento do rosto, todo micro gesto, encena uma máscara e um figurino para quem sabe que está sendo filmado e para quem sabe que está sendo visto e ouvido. Todas se transformam em narradoras e ao mesmo tempo em personagens de suas narrativas, na previsão óbvia de um público para o qual relatam os fatos, contracenando com o diretor que as escuta e com a câmera que as perscruta. E por se tratar de um documentário, ganha força a presença de narradoras na acepção de W. Benjamin (1982), aquelas que trazem à tona a sua própria experiência, que viveram na carne aquilo que é contado, são narradoras da sua própria experiência.

Com as narradoras, mergulha-se, ora quase sem sobressaltos, ora cheio deles, partilhando como interlocutores esta experiência, e são elas, com seus olhares, bocas, mãos, o rosto e sua expressão em close up, que nos conduzem pelas histórias entrecruzadas do cotidiano. É o comum que vem à tona. É o banal contado com naturalidade, com serenidade, com afeto. É o possível e a 
rotina poetizados em minimalismo absoluto. É a vida que se insinua em cena, ou o teatro que se insinua na vida.

E quando nos convencemos de que vale a pena respirar no mesmo ritmo que as narradoras e viver a trama com elas, a voz de E. Coutinho nos acorda e nos alerta que se trata de um documentário: é o narrador das narrativas que se coloca, arguindo, perguntando, conduzindo a trama. O arquiteto da narrativa, que dirige o olhar (o delas e o do espectador) para ele, o diretor. Ele é quem escava a alma dessas mulheres, até que em um dado momento é questionado por uma de suas personagens (quando esta lhe pergunta se conhece o filme Procurando Nemo e responde, ela mesma, que não, ele não deve conhecer, por ser este um filme comercial). Inquirido, Coutinho passa a se justificar: tudo parece um pequeno lapso, a perda do controle do diretor por um átimo, que de pronto se dissipa, para que se restabeleça a ordem. Mas tal desordem é aproveitada na edição - trata-se, inclusive, de uma discussão metalinguística, pois, questionado pela entrevistada quanto ao seu interesse por cinema comercial, a entrevistada toca em uma crítica do cinema, à qual Coutinho responde de forma evasiva. O diálogo entre os dois, entrevistada e diretor, encaminha-se para uma crítica da entrevistada ao intelectual do cinema alternativo. Ela, apenas a entrevistada, avalia e analisa Procurando Nemo como um filme arquetípico, um drama psicológico entre pai e filho. Coutinho deixa muito claro que está, sim, ali, insinuando-se entre aquelas mulheres, e perguntando, ensina como perguntar. Mas também ouvindo, participando, ensina como ouvir e se misturar ao objeto do documentário. Entendendo, interrompendo, divagando com elas, coloca-se como parte dessa história, que só é contada desta forma porque ele, E. Coutinho, na verdade, é o grande narrador, um narrador-participativo. Embora até permita que elas o questionem, deixa claro que foi ele, Eduardo Coutinho, quem permitiu o questionamento, ao não excluir o trecho da edição. Portanto, é o ponto de vista dele. Há o ponto de vista do cinegrafista, mas que é ainda o olhar dele, E. Coutinho, que o dirige. A pergunta que ele formula segue mesclada ao texto 
que ele pediu para ser ensaiado. Trata-se de um narrador um pouco diferente daquele descrito por W. Benjamin (1982), pois agora já um narrador que não apenas viajou para muitos lugares, ou que conhece a tradição, mas um novo narrador, possível apenas pela existência do cinema. É aquele que permite ao espectador ouvir a experiência do outro, reconstituída em tempo presente, e esta experiência é recontada por ele e pelas narradoras, pois ouvimos aquilo que E. Coutinho se propôs a ouvir com imensa atenção e, sobretudo, se propôs compartilhar ao editar o filme e não excluir o que é dado ao público.

Ao se colocar na narrativa, Coutinho faz metalinguagem, pois trabalha sobre a linguagem do audiovisual. E é o processo de linguagem que conta, ou seja, fazendo, ele mostra como faz e/ou como fazer. O foco narrativo deslocase do narrador participativo, em primeira pessoa, às entrevistadas e também às atrizes que representam, para o narrador, ora observador, que auxilia a contar a história sem participar diretamente dela. Ele não é um personagem, mas conduz a trama por meio das perguntas que formula. Desnuda a linguagem do seu próprio modo de criação, e ao abrir espaço para que as atrizes expliquem também como constroem seus métodos de interpretação, coloca a metalinguagem dentro da metalinguagem. São processos de criação que se discutem, além das próprias narrativas, portanto, processos de criação de narrativas. Entretanto, ora o diretor se faz personagem, por meio da metalinguagem que desnuda seu processo criativo, ao deixar marcas de estilo que permitem entrever o criador: o microfone que aparece, a produção que dialoga com ele, ao se deixar inquirir pela entrevistada, a voz grave que questiona em off. É um narrador-criador, e criar é transformar. Tanto que, desta maneira, qualquer história é uma boa história, contada inúmeras vezes e a cada vez, outra, recriada. Coutinho, ao usar a metalinguagem, o texto complexo, a forma como sentido, mais do que um documentário, produz uma obra de arte a partir do corriqueiro, entendido como a própria vida diária, a qual "habita o cotidiano que, apesar de suas ordenações, permite práticas de desvio e a diversidade de experiências. O cotidiano é, em si, uma maneira de 
experimentar a vida" (BRETAS, 2006, p. 30). Trata-se do "lugar da constituição dos laços e da sociabilidade, o cotidiano torna-se palco de uma teatralidade prosaica com cenas, atores e enredos que, paradoxalmente, se repetem e se renovam" (BRETAS, 2006, p. 30). Na medida em que é iluminado por Coutinho, surpreendendo e revelando-se singular, de prosaico, o cotidiano se faz poético.

Valendo-se da noção de cotidiano exposta por Bretas, entende-se que a arte é um tipo de conhecimento, que não se separa do cotidiano, ao aproveitar e iluminar o momento do desvio, da surpresa, da diversidade, da criatividade. A arte é um processo adaptativo / evolutivo, ligado à nossa necessidade de permanência. E a arte é, fundamentalmente, uma forma de comunicação. Nas palavras de Flusser (2008, p. 89), "a comunicação humana é um processo artificial. Baseia-se em artifícios, descobertas, ferramentas e instrumentos, a saber, em símbolos organizados em códigos". Também a arte, assim como a comunicação, é artifício para enganar a solidão profunda de que somos parte. Artifício para fazer esquecer o inescapável, a morte. Flusser (2008, p. 90) explica que este é "o objetivo do mundo codificado que nos circunda":

\footnotetext{
que esqueçamos que ele consiste num tecido artificial que esconde uma natureza sem significado, sem sentido, por ele representada. 0 objetivo da comunicação humana é nos fazer esquecer desse contexto insignificante em que nos encontramos - completamente sozinhos e "incomunicáveis" -, ou seja, é nos fazer esquecer desse mundo em que ocupamos uma cela solitária e em que somos condenados à morte - 0 mundo da "natureza" (FLUSSER, 2008, p. 90).
}

A arte não é dispensável, portanto. Não é supérflua. Ela é uma estratégia de sobrevivência. O documentário de Coutinho é real, na medida em que o real é aquilo que se força sobre nós. E o que se força sobre nós na obra de Coutinho é o cotidiano em sua dupla face de vida e de morte, codificado para ser interpretado, experimentado. Mas também um cotidiano recriado e transformado em poesia, ao ser retirado de seu contexto. Ao codificar o cotidiano das mulheres de Jogo 
de cena, Coutinho cria uma espécie de comunicação dialógica com o público. Mais precisamente, pode ser um modo efetivo de se comunicar, nos moldes da comunicação dialógica / discursiva, definida por V. Flusser:

Para produzir informação, os homens trocam diferentes informações disponíveis na esperança de sintetizar uma nova informação. Essa é a forma de comunicação dialógica. Para preservar, manter a informação, os homens compartilham informações existentes na esperança de que elas, assim compartilhadas, possam resistir melhor ao efeito entrópico da natureza. Essa é a forma de comunicação discursiva (2008, p. 97).

Vivemos em um mundo de complexidade, o que exige adaptação e nos torna continuamente mais complexos. Arte é conhecimento complexo e uma possibilidade para ler o universo que nos cerca. B. Bretas esclarece que:

As práticas cotidianas - conversar, ler, cozinhar, caminhar etc - são atualizações do conhecimento comum, propiciadas pelo exercício de competências e habilidades. Esse tipo de conhecimento, que fundamenta e participa da invenção do cotidiano, para ser conhecido e potencializado, necessariamente, deve passar por um processo de explicitação. Ou seja, deve materializar-se em formas expressivas que deem conta de apresentá-lo e a partir daí possibilitar a crítica e seu desenvolvimento (BRETAS, 2006, pág. 30).

É exatamente o que faz Coutinho ao dar voz às mulheres de Jogo de cena. Com elas, há um processo de explicitação do cotidiano, materializado em corpo, imagem e som. Apresentado a nós de forma poética, por isso, complexa, este cotidiano pode ser experimentado, percebido, criticado e transformado. Da mesma forma, em Crônica de um verão, J. Rouch reinventa o cotidiano ao leválo para a tela. Permite que se reflita não só acerca da experiência de estar vivo, mas também da experimentação de linguagem que pode ser um documentário. Também, assim como E. Coutinho, J. Rouch se utiliza da metalinguagem, incorporando contínuas discussões com a equipe sobre os rumos do filme, até 
o ápice que é o momento em que o filme é exibido a todos aqueles que dele participaram e que podem expressar as suas opiniões - que serão atentamente ouvidas e avaliadas pelos dois diretores.

Da mesma maneira que Coutinho, Rouch e Morin possuem uma capacidade profunda de ouvir, de permitir a fala do outro; são, portanto, narradores que fazem a mediação entre a experiência do cotidiano, relatada por seus entrevistados e o espectador. Em tempos diferentes, mas a partir de processos muito semelhantes, Crônica de um verão e Jogo de cena são filmes cujos cineastas mergulham na alma humana e trazem à tona a beleza da vida transformada em arte.

\section{O evento comunicacional}

Para Marcondes Filho, a comunicação é um fenômeno inapreensível, intraduzível e que não pode ser segmentado. Acrescenta o autor que:

Ela é um processo social, um acontecimento, uma combinação de múltiplos vetores (sociais, históricos, subjetivos, temporais, culturais) que se dá pelo atrito dos corpos e das expressões, algo que ocorre num ambiente, permitindo que se realize, a partir dela, algo novo entre os participantes do ato comunicativo, algo que não possuíam antes e que altera seu estatuto anterior (MARCONDES FILHO, 2008, p. 52).

Seria um traço de relevância, e distintivo, da comunicação, o estatuto de alterar as coisas, de transformá-las, de não permitir que estas se mantenham como antes. Após assistir a Jogo de cena, é natural que ocorra o que consideramos um processo de comunicação efetivo, ou, como na definição de Marcondes Filho, um ato verdadeiramente comunicacional:

Ninguém sai ileso após um ato verdadeiramente comunicacional. Se sair ileso é porque a comunicação não se efetivou, ficou presa nos 
rituais, no formalismo, da repetição infindável do mesmo (Sfez), no giro contínuo do não-acontecido, no fluxo morto de seu movimento recursivo (MARCONDES FILHO, 2008, p. 52).

A comunicação de que nos fala Marcondes está "além da linguagem, além do signo, além da significação, construindo sentidos imprevisíveis, únicos, irrepetíveis, inesperados" (MARCONDES FILHO, 2008, pág. 52). Partindo-se desta premissa é que nos parece justificável a afirmativa de que a arte pode ser um meio eficaz para a comunicação, por ir além da linguagem, além da significação. A arte se constrói em uma linguagem fundamentada na imprevisibilidade, na irrepetibilidade, no inesperado, e entendemos tanto o documentário de Rouch e Morin quanto o de Coutinho como arte. Podemos mencionar os dois filmes como possibilidades de produzir nas audiências um evento comunicacional, centrado na experiência, e que leva os envolvidos para um devir que não descarta a subjetividade da própria experiência, ao contrário, conta com ela.

Assim, para Marcondes Filho (p. 59), não cabe para a comunicação o estabelecimento de um método de investigação, fechado, previsível e inflexível, mas de se estabelecer um percurso a ser construído em processo, longe de um percurso fechado, delimitado, mas:

um emaranhado pulsante e vivo, de momentos, fluxos, vetores, órbitas e cruzamentos. $E$, no interior desse grande mapa, o que interessa à investigação são os interstícios, as superfícies de contato, os pontos de transmissão, ou seja, aquilo que realiza a função do meio. (MARCONDES FILHO, 2008, p. 59)

A arte, como linguagem polissêmica, centrada na experiência, afirmamos, pode ser, portanto, um metáporo para se entender o incorpóreo da comunicação. Colocar a arte e a comunicação em diálogo passa pela opção de um pensamento nômade, movediço, atento às entrelinhas, às brechas, aos possíveis, e não aos prováveis. É esta a comunicação que nos interessa, libertária e provisória. 
Crônica de um verão e Jogo de cena, obras de arte, são filmes que permitem entender que o método se faz em processo, e que a comunicação é um evento transformador, já que, depois dela, a comunicação efetiva proporcionada pela experiência de filmes como estes, nada restará igual, quer sejam os diretores, os atores ou os espectadores. 


\section{Referências}

BENJAMIN, W. "O narrador: considerações sobre a obra de Nikolai Leskov". In: Magia, técnica, arte, política. São Paulo: Brasiliense, 1982.

BRETAS, B. "Interações cotidianas". In: GUIMARÃES, C. FRANÇA, V. Na mídia, na rua: narrativas do cotidiano. Belo Horizonte: Autêntica, 2006.

FLUSSER, V. O mundo codificado. São Paulo: Cosac Naify, 2008.

GONÇALVES, G. S. Panorama do documentário no Brasil. Amazonas: Uninorte, 2006. Disponível em: www.doc.ubi.pt, 79-91. Acessado em: 10 fev. 2011.

GROTOWSKY, J. Em busca de um teatro pobre. Rio de Janeiro: Civilização Brasileira, 1987. LOTMAN, I. A estrutura do texto artístico. Lisboa: Estampa, 1978.

MARCONDES FILHO, Ciro. "Comunicação, uma ciência anexata e contudo rigorosa". In: Comunicação: novo objeto, novas teorias? Teresina: EDUFPI, 2008.

MORIN, E. "Crônica de um filme". In: MORIN, E.; ROUCH, J. Crônica de um verão. Rio de Janeiro: Coleção Videofilmes, 2008.

PEIRCE, C. S. Semiótica. São Paulo: Perspectiva, 1977. 